\title{
Integrative Analysis of Self-Regulated Learning Ability and Problem-Solving Among Experts and Novices
}

\author{
Xiru Sun ${ }^{1, *}$ \\ ${ }^{1}$ University of California, Los Angeles, Los Angeles, The United States \\ *Corresponding author email: sxrharbin@g.ucla.edu
}

\begin{abstract}
One primary goal for educational professionals is to guide learners through learning and assist individuals in achieving mastery from novelty (expert-level would be ideal) in specific fields. Nevertheless, along with this transformation, in many academic subjects like physics, math and computer science, novices in the beginning stage are often restricted by unsuccessful application of their cognitive ability in problem-solving. One core distinction between experts and novices is the self-regulated learning ability. Experts tend to be more sophisticated in planning, making strategies, and monitoring self-performance. To understand the integration of self-regulation and experts' problem-solving ability, the paper will 1). distinguish how experts and novices solve problems differently, 2). explore self-monitoring and applicable training to foster greater self-regulation, and 3). integrate two research areas to examine how to expertise in specific areas through self-regulation training. And finally, the educational implications will be briefly addressed.
\end{abstract}

Keywords: Self-regulated Learning, Self-Monitoring, Problem-Solving, Expert Learning, Novice Learning

\section{INTRODUCTION}

Self-regulated learning has been defined as 'the degree to which [students] are metacognitively, motivationally, and behaviorally active participants in their own learning processes' [1]. It has been extensively studied due to its close connection to and indication for successful achievement and distinct performances [2]. Further, unlike other fixed personal traits, self-regulated learning has successfully been taught and modified [3]. One major emphasis of researchers studying strategies to enhance an individual's self-regulated learning is distinguishing between expert and novices learning [4].

'Expert' is someone who has superior knowledge in a specific domain than those non-experts; in the problem-solving process, they would spend more effort to 'define problem' and make use of their prior knowledge than novices [5]. Among all differences in problem-solving between experts and novices, such as the distinction in their knowledge base, their thinking mode or their strategy-used, three main characters would be drawn upon deep or superficial structural level [6], optimal or required strategy [7], and the efficiency of memories [8].

\section{HOW DO EXPERTS DIFFER FROM NOVICES REGARDING PROBLEM- SOLVING?}

One significant advantage of expertise thinking is the ability to draw essence through the phenomenon. To solve problems in areas like math and science, whilst novices focus straight on surface features [6] to use their own languages to explain conditions to satisfy the requirement, experts tend to draw on deep structures of the problem, starting with strategy use and decision making. Build upon the surface approach, an in-depth understanding of the question is to categorize, distinguish related and unrelated information, and to choose and utilize strategies properly. Chi and his colleagues [9] also found that novices would cue on 'detailed information (e.g., equations and specific facts) rather than more general principles and concepts' [6] in problem-solving procedures. For example, when a set of 20 labels are presented, novices will categorize based on the surface feature as 'blocks on incline'. At the same time, experts will describe the situation as 'Newton's Second Law' [9]. In general, the iceberg's surface is easy to notice when its deep root is not visible to everyone. 
Another evident context to differentiate experts from novices is the tactic or strategy they use in problem-solving [7]. The construction of expertise absorbs schema in that specific domain. When experts have experienced quantitatively structured schema, they are more likely to choose the optimal solution and use their existing solid knowledge and principles to come up with solutions. On the contrary, beginners would work backwards by identifying requirements, finding equations from the superficial level, and then trial-anderror to test feasibilities until they succeed [10].

Additionally, in a specific domain of expertise, experts and novices tend to have various memory efficiency [8]. Depending on their prior knowledge of schema and structures, which could be used as a filter for information processing [10], experts tend to have a higher efficiency of short-term memory. On the other hand, because novices have not developed sufficient schema for every possible problem they encounter, they are more likely to fail in encoding and retrieving from their working memory, resulting in lower efficiency of memory.

Another measurement for memory efficiency is through the quantity and accuracy of tasks developed by Chase and Simon [8] to differentiate experts and novices' memory. For example, when testing on the placement of chess pieces on the chessboard, because experts, in general, have encountered more than 50,000 chunks of configuration, than have a better performance in both numbers and precisions of pieces to recall chess positions than novices who attempt to memorize each piece separately [10].

\section{HOW TO DEVELOP SELF- REGULATED LEARNING ABILITY}

The ability to self-regulate one's cognition and behaviour are essential to achieving success and expertise in specific domains. Therefore, extensive researches have been conducted to train students within different age groups in different subject areas. Baumeister, Vohs, and Tice have defined selfregulation as the capacity to change an individual's response by restraining 'unwanted urges to gain control' [11]. The prevailing model developed by Zimmerman has divided self-regulated learning into three procedural and interrelated phases: the forethought phase, the performance phase, and the self-reflection phase [3].

Before taking action, the forethought phase is the effort to conduct strategic planning and goal setting [12]. The planning has to be realistic and customized based on personal characteristics and preferences (e.g., what, when, where, how to achieve), and the goal planning should be as specific as possible (e.g., short and longterm goals, academic and work goals) [12].
During the performance phase, the self-monitored or self-regulated learning depends on self-control, including self-instruction, application of task strategy, imagery, and attention focusing [3]. To resist distractions, several cognitive strategies could be used, such as environmental structuring (e.g., study better at home or library), time management (e.g., scheduling) and personal feedback (e.g., keep a tangible record of completion) [13]. Common tools such as summarizing and highlighting are also under-estimated for their usefulness regarding performance enhancement. The motivation for the task, in this phase, is one decisive factor for the achievement of performance. If the learner is highly motivated, he or she would be more likely to perform positively, and vice versa. So, any strategy to increase an individual's motivation, intrinsically or extrinsically, would also be helpful to create favourable consequences.

The final phase in Zimmerman's self-regulated learning theory is the self-reflection phase, which contains self-judgment and future adaptive strategy [12]. After the task has been done, the reflection on the task is a significant predictor for future success in related areas. However, this reflection is also highly related to teachers and supervisors' feedbacks. After receiving feedback and judgments, the strategic adaptation to change would benefit future results and create a coefficient loop when conducting a new task with the beginner phase of the forethought phase.

The theory of self-regulated learning, from another perspective, has a close bond to metacognitive awareness [14]. The inventory developed by Schraw and Dennison examining adults' metacognitive awareness found that self-monitoring correlates with test performance and that cognitive regulation correlates with planning, monitoring, and strategy use [14]. Therefore, it would also be helpful to use MAI (Metacognitive Awareness Inventory) as an aiding tool to plan future metacognitive training and a monitoring tool to apply suitable strategies targeting different metacognitive concerns [14].

\section{RESEARCH METHODS IN SELF- REGULATION AND EXPERTISE PROBLEM-SOLVING}

In both research areas, there are more similarities than differences. Self-regulated learning is prevailing in education due to its impact on learning inside and beyond the school context [12]. Moreover, as we mentioned at the beginning of the paper, how to instruct students to think like an expert to solve problems in a specific domain is a long-term goal for educators. The significance of both areas has largely drawn researchers' attention, resulting in research being conducted across countries, cultures, domains, and peoples. For example, Vohs and Baumeister make a thorough discussion on 
diverse areas in relation to self-regulation such as cognitive neuroscience, romantic relationship, religion, work setting, and financial well-being [15]; Burnette et al., has developed a meta-analysis on the different context of self-control with more than 28,000 participates, concluded the importance of self-control theory and the improving performance through trainings [16]. Furthermore, there are intensive studies of problem-solving of experts and expertise training in academic subjects [17], chess [18], sports [19], technology [20], and teaching [21] as well.

With this broad scope of research in the two areas, qualitatively and quantitively, research was conducted in problem-solving ability and self-monitoring ability [22]. However, while the self-monitoring researches are mostly in-depth qualitative evaluation and reflections, many research on how experts solve problems differently is carried out through quantitative analysis [22]. When developing the ability to regulate oneself, it is our intuition to have a strong and in-depth understanding of its characteristics and strategies to be used. In contrast, by evaluating a large number of subjects (e.g., studying experts in different fields), it is more credible to make conclusions about 'experts' characteristics' so that we could absorb the essence and discard unnecessariness.

\section{INTEGRATION OF SELF- REGULATION AND EXPERTISE PROBLEM-SOLVING}

To achieve the mastery level of expertise, Ericsson, Krampe, and Tesch-Römer proposed the concept of deliberate practice as structured trainings to promote 'optimal opportunities for learning and skill acquisition' [23], consisting of essential features like specific goal setting, intensive trainings and the ability to selfmonitoring and conduct future adaptive strategies through feedback. In contrast with novices who cannot monitor their study process (e.g., what they know and what they have learned), experts are well-aware of their strengths and abilities to maximize their potentials [23]. They planned to study the right thing, at the right place, for the right reason, and in the right way to deliberately regulate their personalized approaches to learning [24]. In their learning process, all behaviours and conditions are monitored to maintain the sustainability on when to continue, when to modify and when to terminate; they also keep in their mind on how to use self-test and selfquestioning efficiently and adequately as feedbacks for misunderstandings and omissions [24].

Other researches were also extended to explain how self-regulated strategies were different among experts and novices. In Cleary and Zimmerman's study about 'how expert athletes and novice athletes distinct in their self-regulation,' one finding is that during both the forethought phase and self-reflection phase, experts have shown better strategy to reflect and monitor on their self-performance [25]. Further, Ertmer and Newby suggested that during the performance phase, learners actively use their skills like goal setting or environmental control to cognitively choose the appropriate strategy so that the metacognitive knowledge and adjusting process become their strategic control and personal characteristics [24]. For experts' future study, what has been developed in this learning task is now in their stored memory and could be used for the next task such that experts keep refining their metacognition, creating a more significant gap between experts and novices if novices are not making any progress toward metacognitive ability.

\section{EDUCATIONAL IMPLICATION}

Traditional learning has put much effort into elaborated instruction, while in recent years, the importance of reflection and metacognition has also come to our sight. Though the process of selfmonitoring and self-regulating should be self-directed and self-learned, it is argued by researchers and teaching professionals that the ability of 'learning how to learn' has to be taught. That teacher's guidance plays an essential role to develop student's habits of regulation [24]. Some also claimed that the metacognitive skill has no apparent difference from other skills that need to be taught due to the necessity to receive feedback [24]. In the scenario of problemsolving, even if students have a thorough understanding of how experts perform differently through superior self-regulated strategy, it may still be an unachievable goal to 'think like an expert' without further instruction.

Consequently, as students start to realize that throughout the process of problem-solving, experts have the awareness to constantly check for mistakes and neglects in combination with heightened motivation and self-regulated ability, they are ready to and in need of developing self-monitoring skills through practice. Furthermore, if they use the strategies being taught and utilize them in different subjects and learning contexts, they would have a bigger chance to master the skill to self-regulate when encountering problems.

Finally, what kind of training should be provided for students and if those trainings are working would be our least concern. Many pieces of evidence have shown that both the ability of self-regulation and the ability of problem-solving could be improved through training. For example, Ericsson described the attempt of deliberate practicing as deliberate problem solving because it involves 'forming a cognitive representation of the task, choosing appropriate techniques or strategies, and evaluating one's effectiveness' [26]. In addition, Bielaczyc, Pirolli, \& Brown's research also found that specific self-regulation training and strategies could result in better learning and better 
performance in problem-solving, with the simplest but very effective strategy to explicitly instruct students about purpose and content of strategies, to demonstrate through examples, and to provide guided practice activity [27].

\section{CONCLUSION}

In experts' specific domain of study, through every task, they are always able to go beyond the given task and achieve a deeper-level of understanding as novices regularly scan through the surface. Specifically, in the self-directed learning process, experts are more likely to perform better in three phases of self-regulated learning: forethought phase, performance phase, and selfreflection phase. Thus, to be an 'expert' in a specific field of study, talent and practice are not the only requirements. Deliberate input, proper guidance, and also self-regulated ability are vital elements to achieve better performances.

\section{REFERENCES}

[1] Zimmerman BJ. Motivational sources and outcomes of self-regulated learning and performance. In: Zimmerman B, Schunk D, eds. Handbook of Self-Regulation of Learning and Performance. New York, NY: Routledge 2011;4964.

[2] Brydges R, Butler D. A reflective analysis of medical education research on self-regulation in learning and practice. Med Educ 2012;46:71-9.

[3] Zimmerman BJ. Attaining self-regulation: a social cognitive perspective. In: Boekaerts M, Pintrich PR, Zeidner M, eds. Handbook of Self-Regulation. San Diego, CA: Academic Press 2000;13-3

[4] Artino Jr, A. R., Cleary, T. J., Dong, T., Hemmer, P. A., \& Durning, S. J. (2014). Exploring clinical reasoning in novices: a self-regulated learning microanalytic assessment approach. Medical education, 48(3), 280-291.

[5] Brand-Gruwel, S., Wopereis, I., \& Vermetten, Y. (2005). Information problem solving by experts and novices: Analysis of a complex cognitive skill. Computers in Human Behavior, 21(3), 487508 .

[6] Hardiman, P. T., Dufresne, R., \& Mestre, J. P. (1989). The relation between problem categorization and problem solving among experts and novices. Memory \& cognition, 17(5), 627-638.

[7] Lazonder, A. W. (2000). Exploring novice users' training needs in searching information on the WWW. Journal of computer assisted learning, 16(4), 326-335.
[8] Chase, W. G., \& Simon, H. A. (1973). The mind's eye in chess. In W. G. Chase (Ed.), Visual information processing (pp. 215-281). New York: Academic Press.

[9] Chi, M. T., Feltovich, P. J., \& Glaser, R. (1981). Categorization and representation of physics problems by experts and novices. Cognitive science, 5(2), 121-152.

[10] Feldon, D. F. (2007). The implications of research on expertise for curriculum and pedagogy. Educational Psychology Review, 19(2), 91-110.

[11] Baumeister, R. F., Vohs, K. D., \& Tice, D. M. (2007). The strength model of self-control. Current directions in psychological science, 16(6), 351-355.

[12] Leidinger, M., \& Perels, F. (2012). Training selfregulated learning in the classroom: Development and evaluation of learning materials to train selfregulated learning during regular mathematics lessons at primary school. Education Research International, 2012.

[13] Zimmerman, B. J. (1989). A social cognitive view of self-regulated academic learning. Journal of educational psychology, 81(3), 329.

[14] Schraw, G., \& Dennison, R. S. (1994). Assessing metacognitive awareness. Contemporary educational psychology, 19(4), 460-475.

[15] Vohs, K. D., \& Baumeister, R. F. (Eds.). (2016). Handbook of self-regulation: Research, theory, and applications. Guilford Publications.

[16] Burnette, J. L., O'boyle, E. H., VanEpps, E. M., Pollack, J. M., \& Finkel, E. J. (2013). Mind-sets matter: A meta-analytic review of implicit theories and self-regulation. Psychological bulletin, 139(3), 655.

[17] D'Zurilla, T. J., \& Sheedy, C. F. (1992). The relation between social problem-solving ability and subsequent level of academic competence in college students. Cognitive therapy and research, 16(5), 589-599.

[18] Bilalić, M., McLeod, P., \& Gobet, F. (2009). Specialization effect and its influence on memory and problem solving in expert chess players. Cognitive science, 33(6), 1117-1143.

[19] Hristovski, R., Davids, K., Passos, P., \& Araujo, D. (2012). Sport performance as a domain of creative problem solving for self-organizing performerenvironment systems. The Open Sports Sciences Journal, 5(1).

[20] Hennessy, S., \& Murphy, P. (1999). The potential for collaborative problem solving in design and 
technology. International journal of technology and design education, 9(1), 1-36.

[21] Carson, J. (2007). A problem with problem solving: Teaching thinking without teaching knowledge. The mathematics educator, 17(2).

[22] Eyisi, D. (2016). The usefulness of qualitative and quantitative approaches and methods in researching problem-solving ability in science education curriculum. Journal of Education and Practice, 7(15), 91-100.

[23] Ericsson, K. A., Krampe, R. T., \& Tesch-Römer, C. (1993). The role of deliberate practice in the acquisition of expert performance. Psychological review, 100(3), 363.

[24] Ertmer, P. A., \& Newby, T. J. (1996). The expert learner: Strategic, self-regulated, and reflective. Instructional science, 24(1), 1-24.

[25] Cleary, T. J., \& Zimmerman, B. J. (2001). Selfregulation differences during athletic practice by experts, non-experts, and novices. Journal of Applied Sport Psychology, 13(2), 185-206.

[26] Zimmerman, B. J. (2006). Development and Adaptation of Expertise: The Role of SelfRegulatory Processes and Beliefs. In K. A. Ericsson, N. Charness, P. J. Feltovich, \& R. R. Hoffman (Eds.), The Cambridge handbook of expertise and expert performance (pp. 705-722). New York, NY, US: Cambridge University Press.

[27] Bielaczyc, K., Pirolli, P. L., \& Brown, A. L. (1995). Training in self-explanation and self-regulation strategies: Investigating the effects of knowledge acquisition activities on problem solving. 